\title{
Pre-diabetes: Is this a clinical problem with pharmaceutical solutions?
}

\author{
Sayeeda Rahman ${ }^{1}$, Md Anwarul Azim Majumder ${ }^{2}$
}

${ }^{1,2}$ Lecturer, Department of Clinical Sciences, School of Medical Sciences, University of Bradford, West Yorkshire, Bradford, UK.

Prevalence of prediabetes is increasing significantly and poses a challenge to both developed and developing nations alike. ${ }^{1}$ The vast majority of people with prediabetes are unaware of the condition and they are at very high risk of developing diabetes. ${ }^{2}$ According to the IDA, approximately one-fifth of all adults with diabetes in the world live in the South-East Asia region. ${ }^{3}$ It has been also forecasted that people with diabetes in the region will increase to 120.9 million by 2030 , or $10.2 \%$ of the adult population. It was also pointed out that there were 23.8 million people with impaired glucose tolerance (IGT) in 2011, and this will increase to 38.6 million by $2030 .^{3}$ The number of people with diabetes in India, Bangladesh and Sri Lanka make up $99 \%$ of the total for the region (IDF). ${ }^{3}$ It has been predicted that there will be about 471 million people with prediabetes globally by $2035 .^{4}$ There are 86 million, or more than $1 / 3$ rd of the population, in the $\mathrm{USA}^{5}$ and an estimated 77.2 million people in India ${ }^{6}$ who are suffering from pre -diabetes. The condition is associated with enhanced risk of developing micro- and macrovascular complications, which are more common in people with prediabetes than individuals at normal blood glucose levels. ${ }^{2,8-13}$ Most studies demonstrated that $5 \%$ to $10 \%$ of people with prediabetes progress to diabetes each year ${ }^{14,15}$ and with the same proportion converting back to normoglycemia. ${ }^{15}$

The treatment diabetes imposes a substantial burden on the economy of a country. People with diabetes have medical costs that are 2.3 times more than patients without diabetes. ${ }^{16}$ Dramatic rise in costs for those with prediabetes and undiagnosed diabetes is also 'alarming'. The national cost associated with prediabetes in the USA is \$44 billion (2012 estimate) and \$510 annually per person (medical costs only). ${ }^{5}$ The annual cost of diabetes in Bangladesh is US\$314/person and total estimated annual cost to treat diabetes is US\$1.5 billion, which is a large burden for a developing country like Bangladesh. ${ }^{17}$ Increased costs associated with prediabetes and undiagnosed diabetes highlight the growing importance of prevention and early intervention and treatment.

There are more controversies than consensus in defining prediabetes among different authorities. The American Diabetes Association (ADA) ${ }^{18}$ in 1997 and World Health Organization (WHO) ${ }^{19}$ in 1999 defined the criterion for diagnosis of diabetes to a fasting plasma glucose concentration of $\geq 7.0 \mathrm{mmol} / \mathrm{L}(126 \mathrm{mg} / \mathrm{dL})$, and impaired fasting glucose (IFG) [6.1-6.9 mmol/L (110$125 \mathrm{mg} / \mathrm{dL})]$. However, ADA in 2003 recommended reducing the threshold for IFG from $6.1 \mathrm{mmol} / \mathrm{L}$ $(110 \mathrm{mg} / \mathrm{dL})$ to $5.6 \mathrm{mmol} / \mathrm{L}(100 \mathrm{mg} / \mathrm{dL})$ to improve the prediction of diabetes risk. ${ }^{20}$ This was not endorsed by the WHO or any other authorities. ${ }^{21}$ Concerns were expressed that this new IFG level would roughly double the prevalence of sub-diabetes. ${ }^{22}$ The expanded IFG level would include people at lower risk of diabetes and cardiovascular disease who may perhaps be less likely to benefit from medical interventions. ${ }^{22}$

Prediabetes can also be diagnosed by glycosylated hemoglobin $\mathrm{A} 1 \mathrm{C}(\mathrm{HbA1c})$. There was reasonable consensus on using $\mathrm{HbA} 1 \mathrm{c}>6.5 \%(48 \mathrm{mmol} / \mathrm{mol})$ to diagnose diabetes ${ }^{23-25}$ and less around pre-diabetes. ${ }^{22}$ The International Expert Committee ${ }^{25}$ and the National Institute for Health and Clinical Excellence ${ }^{26}$ (UKbased) supported using 6.0-6.4\% (42-46 $\mathrm{mmol} / \mathrm{mol})$ for prediabetes range and recommended intervention if HbAlc $\geq 6.0 \%$ and may be below this level for patients who are at increased risk. In 2010, the ADA reduced the threshold for prediabetes from $6.0 \%$ to $5.7 \%,{ }^{23}$ a decision not supported by WHO or other agencies. ${ }^{22}$ These changes caused a lot of havoc! For example, if this guideline is used, over half of all Chinese adults would have prediabetes i.e. approximately 493 million people - and this should be considered an epidemic situation! $!^{22}$

Several clinical trials have shown that intensive lifestyle interventions and the use of pharmacological agents can significantly reduce the incidence of overt DM in individuals with prediabetes. Three major trials of diabetes prevention with intensive lifestyle counselling conducted in China, ${ }^{27}$ Finland $^{28}$ and America ${ }^{29}$ reported a $40 \%-60 \%$ relative risk reduction in the incidence of diabetes, with one case of diabetes being 'averted' by treating around seven people with IGT for three years. ${ }^{22}$ Several oral agents including metformin, thiazolidinedione's (TZDs), acarbose and insulin have been evaluated for the prevention of DM in patients with prediabetes; however, these studies have only had modest success and reported various side-effects and toxicity. ${ }^{30}$

So the question is: should we screen and diagnose prediabetes? The criterion recommended by the ADA overestimated number of the prediabetes. Approximately, there are 3.2 million people in the UK suffering from T2DM, but approximately 16 million people would fall into the ADA's prediabetes category. ${ }^{22}$ The ADA category of prediabetes includes millions of people who are at a much lower risk of

Correspondence: Dr. Sayeeda Rahman, Lecturer, Department of Clinical Sciences, School of Medical Sciences, Faculty of Life Sciences, University of Bradford, Bradford BD7 1DP, West Yorkshire, UK. E-mail: srahman6@bradford.ac.uk.

South East Asia Journal of Public Health 2016;6(1):46-48® 2016 Rahman and Majumder, publisher and licensee Public Health Foundation Bangladesh. This is an Open Access article which permits unrestricted non-commercial use, provided the original work is properly cited. 
progressing to diabetes, for whom any benefit from treatment is currently unknown. ${ }^{22}$ Prof John Yudkin, of UCL said: 'Pre-diabetes is an artificial category with virtually zero clinical relevance. There is no proven benefit of giving diabetes treatment drugs to people in this category before they develop diabetes, particularly since many of them would not go on to develop diabetes anyway'.22

Should we treat the prediabetic patients with medication? Do we have enough resources to treat these so called 'patients'? Will this distract us from managing and treating the huge number of diabetic patients? Moreover, there is no evidence that earlier intervention based on the ADA's criteria can lead to either improved health or a reduced risk of death. The treatments to reduce blood sugar in prediabetes patients only delayed the onset of T2DM by a few years, and until now there is no evidence of long-term health benefits. ${ }^{30}$ Even from improving health, the drugs can cause more side-effects and even death! Professor Yudkin and Professor Montori argued the situation by highlighting the findings of the DREAM study: " 14 in 100 people were prevented (or postponed) from developing diabetes by taking rosiglitazone for 3 years. This means that 86 in 100 healthy people who weren't going to develop diabetes in three years were put on a drug that causes heart failure and fractures and has been under suspicion of increasing cardiovascular risk'. ${ }^{22}$ Troglitazone and Rosiglitazone have been withdrawn from the market or advised to be used cautiously due their toxicity or adverse effects. They also mentioned that labeling people with moderately high blood sugar as prediabetic is a drastically premature measure with no medical value and huge financial, social and emotional costs. ${ }^{22}$ Moreover, a range of newer and more expensive drugs are being explored (such as DPP-4 inhibitors and GLP-1 receptor agonists) as treatments for pre-diabetes which will incur more costs ${ }^{30}$ and will divert resources from priority health issues. It was emphasized that we should not consider prediabetes as a clinical problem with pharmaceutical solutions'. ${ }^{32}$ Rather, money and efforts should focus on improving priority public health issues. Healthy diet and physical activity should be considered as the best options to prevent and to tackle prediabetes and diabetes. To harmonize current definitions of prediabetes, further long-term clinical research is required by considering clinically relevant outcome parameters based on different diagnostic criteria. $^{33}$

\section{References}

1. Ghody P, Shikha D, Karam J, Bahtiyar G. Identifying prediabetes - Is it beneficial in the long run? Maturitas 2015;81(2):282-6.

2. Rahman S, Majumder MAA, Rahman ARA. Treatment of diabetic vasculopathy: An overview. Res Rep Endocr Disord 2011;1:21-36.

3. International Diabetes Federation. IDF Atlas 2015. http://www.idf.org/diabetesatlas/5e/southeast-asia (accessed June 2016)

4. International Diabetes Federation. IDF Diabetes Atlas. $6^{\text {th }}$ ed. Brussels, Belgium: International Diabetes Federation, 2013.

5. Centers for Disease Control and Prevention.
National Diabetes Statistics Report: Estimates of Diabtes and Its Burden in the United States, 2014. Atlanta, GA: US Department of Health and Human Services, 2014.

6. More than 77 million people in India have pre-diabetes: expert. The Hindu. Jan 27, 2014.

7. Rahman S. Diabetes and macrovasculopthy: Double trouble. South Asia J Public Health 2013:3(2):1-3.

8. Rahman, S; Aziz Al-Shafi Ismail; Shaiful Bhari Ismail; Nyi Nyi Naing, A Rashid A Rahman. Effect of ramipril/rosiglitazone in Diabetic vasculopathy: needs higher dose or longer treatment? Clin Pharmacol 2010;2; 83-7.

9. Rahman, S; Aziz Al-Shafi Ismail; Shaiful Bhari Ismail; Nyi Nyi Naing, A Rashid A Rahman. Increased arterial stiffness in normoglycaemic offspring of newly diagnosed, never treated type 2 diabetic and impaired glucose tolerant parents. Br J Diabetes Vasc Dis 2009;9:65-8.

10. Rahman, S; Aziz Al-Shafi Ismail, A Rashid A Rahman. Treatment of diabetes vasculopathy with rosiglitazone and ramipril: Hype or Hope? Int J Diabetes Dev Ctries 2009;29:110-7.

11. Rahman, S; Aziz Al-Shafi Ismail; Shaiful Bhari Ismail; Nyi Nyi Naing, A Rashid A Rahman. Early manifestation of macrovasculopathy in newly diagnosed never treated Type 2 diabetic and impaired glucose tolerance patients. Diabetes Res Clin Pract 2008;80:253-8.

12. Rahman, S; Aziz Al-Shafi Ismail; Shaiful Bhari Ismail; Nyi Nyi Naing, A Rashid A Rahman (2007). Effect of Rosiglitazone and Ramipril on preclinical vasculopathy in newly diagnosed, untreated T2DM and IGT patients: One-year randomised, double-blind and placebo-controlled study. Eur J Clin Pharmacol 2007;63:733-741.

13. Rahman S, Tahminur Rahman, Aziz Al-Shafi Ismail and Abdul Rashid A Rahman. Diabetesassociated macrovasculopathy: pathophysiology and pathogenesis. Diabetes Obes Metab 2007;9:767-80.

14. Gerstein HC, Santaguida P, Raina P, Morrison $\mathrm{KM}$, Balion $\mathrm{C}$, Hunt $\mathrm{D}$, et al. Annual incidence and relative risk of diabetes in people with various categories of dysglycemia: a systematic overview and meta-analysis of prospective studies. Diabetes Res Clin Pract 2007;78(3):30512.

15. Tabak AG, Herder C, Rathmann W, Brunner EJ, Kivimaki M. Prediabetes: a high-risk state for diabetes development. Lancet 2012; 379 (9833):2279-90.

16. American Diabetes Association1. Economic Costs of Diabetes in the U.S. in 2012. Diabetes Care 2013;36(4):1033-46.

17. Afroz A, Habib SH, Chowdhury HA, Paul D, Shahjahan M, Hafez MA, et al. Healthcare cost of type 2 diabetes mellitus in Bangladesh: A hospital-based study. Int J Diabetes Dev Ctries 2016;36(2): 235-41.

18. Expert Committee on the Diagnosis and Classifi- 
cation of Diabetes Mellitus. Report of the expert committee on the diagnosis and classification of diabetes mellitus. Diabetes Care 1997;20:118397.

19. World Health Organization. Definition, diagnosis and classification of diabetes mellitus and its complications: report of a WHO consultation. Part 1. Diagnosis and classification of diabetes mellitus. Geneva: WHO, 1999.

20. Expert Committee on the Diagnosis and Classification of Diabetes Mellitus. Follow-up report on the diagnosis of diabetes mellitus. Diabetes Care 2003;26:3160-7.

21. World Health Organization. Definition and diagnosis of diabetes mellitus and intermediate hyperglycemia: report of a WHO/IDF consultation. Geneva: WHO, 2006.

22. Yudkin JS, Montori VM. The epidemic of pre-diabetes: the medicine and the politics. $B M J$ 2014;349:g4485.

23. American Diabetes Association. Diagnosis and classification of diabetes mellitus. Diabetes Care 2010;33(suppl 1):S62-9.

24. International Expert Committee. International expert committee report on the role of the A1c assay in the diagnosis of diabetes. Diabetes Care 2009;32:1327-34

25. World Health Organization. Use of glycated haemoglobin (HbAlc) in the diagnosis of diabetes mellitus. abbreviated report of a WHO consultation. Geneva: WHO, 2011.
26. National Institute for Health and Care Excellence. Preventing type 2 diabetes: risk identification and interventions for individuals at high risk. NICE Public Health Guidance 38. London: NICE, 2012.

27. Pan XR, Li GW, Hu YH, Wang JX, Yang WY, An ZX, et al. Effects of diet and exercise in preventing NIDDM in people with impaired glucose tolerance. The Da Qing IGT and Diabetes Study. Diabetes Care 1997;20(4):53744.

28. Tuomilehto J, Lindström J, Eriksson JG, Valle TT, Hämäläinen $\mathrm{H}$, Ilanne-Parikka $\mathrm{P}$, et al. Prevention of type 2 diabetes mellitus by changes in lifestyle among subjects with impaired glucose tolerance. $N$ Engl $J$ Med 2001;344:1343-50.

29. Knowler WC, Barrett-Connor E, Fowler SE, Hamman RF, Lachin JM, Walker EA, Nathan DM; Diabetes Prevention Program Research Group. Reduction in the incidence of type 2 diabetes with lifestyle intervention or metformin. N Engl J Med 2002;346:393-403.

30. Bansal N. Prediabetes diagnosis and treatment: A review. World J Diabetes 2015; 6(2): 296-303.

31. Bosch J, Yusuf S, Gerstein HC, Pogue J, Sheridan P, Dagenais G, et al. Effect of Ramipril on the Incidence of Diabetes. $N$ Engl J Med 2006;355(15):1551-62.

32. UCL News. Pre-diabetes label 'unhelpful and unnecessary. https://www.ucl.ac.uk/news/newsarticles/0714/160714-Pre-diabetes-labelunnecessary-and-unhelpful/ (accessed June 2016) 